\title{
Correlation between the NPPB gene promoter c.-1298 G/T polymorphism site and pulse pressure in the Chinese Han population
}

\author{
K. Zeng ${ }^{1}$ X.D. Wu' ${ }^{2}$ H.D. Cai ${ }^{1}$, Y.G. Gao ${ }^{1}$, G. Li ${ }^{3}$, Q.C. Liu $^{4,5}$, F. Gao ${ }^{6}$, \\ J.H. Chen ${ }^{7}$ and C.Z. Lin ${ }^{1}$ \\ ${ }^{1}$ Department of Anesthesiology, the First Affiliated Hospital, \\ Fujian Medical University, Fuzhou, China \\ ${ }^{2}$ Department of Anesthesiology, Fujian Provincial Hospital, \\ Provincial Clinical College of Fujian Medical University, Fuzhou, Fujian, China \\ ${ }^{3}$ Department of Cardiology, The First Affiliated Hospital, \\ Fujian Medical University, Fuzhou, China \\ ${ }^{4}$ Department of Laboratory Medicine, the First Affiliated Hospital, \\ Fujian Medical University, Fuzhou, China \\ ${ }^{5}$ Department of Gene Diagnosis, Fujian Medical University, Fuzhou, China \\ ${ }^{6}$ Department of Pathology, the First Affiliated Hospital, \\ Fujian Medical University, Fuzhou, China \\ ${ }^{7}$ Department of Statistics, Fuzhou General Hospital, Fuzhou, Fujian, China
}

Corresponding author: C.Z. Lin

E-mail: caizhu_lin@163.com

Genet. Mol. Res. 13 (2): 3265-3274 (2014)

Received August 21, 2013

Accepted December 16, 2013

Published April 29, 2014

DOI http://dx.doi.org/10.4238/2014.April.29.4

\begin{abstract}
The aim of this study was to investigate the correlation between the natriuretic peptide precursor B (NPPB) gene single nucleotide polymorphism (SNP) c.-1298 G/T and pulse pressure (PP) of the Chinese Han population and the association between genotype and clinical indicators of hypertension. Peripheral blood was collected from 180 unrelated patients with hypertension and 540 healthy volunteers (control group), and DNA was extracted to amplify the
\end{abstract}


5'-flanking region and 2 exons of the NPPB gene by polymerase chain reaction; the fragment was sequenced after purification. The clinical data of all subjects were recorded, the distribution of the NPPB gene c.-1298 G/T polymorphism was determined, and differences in clinical indicators between the two groups were evaluated. The mean arterial pressure PP, and creatinine levels were significantly higher in the hypertension group than in the control group $(\mathrm{P}<0.05)$, but no other clinical indicators differed between the groups. There were no significant differences in genotype frequency and distribution of the NPPB gene c.-1298 G/T polymorphism between the hypertension group and the control group $(\mathrm{P}>0.05)$; in the control group, the mean PP of individuals with the SNP c.-1298 GG genotype was greater than that of individuals with the GT+TT genotype $(\mathrm{P}<0.05)$. In conclusion, there was no significant correlation between the NPPB gene c.-1298 G/T polymorphism and the incidence of essential hypertension in the Han population; however, the PP of the SNP c.1298 GG genotype was greater than that of the GT+TT genotype in the control group.

Key words: NPPB gene; Polymorphism; Essential hypertension; Pulse pressure

\section{INTRODUCTION}

Essential hypertension is a risk factor of a variety of cardiovascular diseases (CVDs) and cerebrovascular diseases, which affects the structure and function of vital organs such as the heart, brain, and kidney, eventually leading to the failure of these organs. The occurrence of essential hypertension is mainly related to genetics, diet, mental stress, and weight, among other factors. Currently, the standards of diagnosis, treatment, and assessment of hypertension are as follows: systolic blood pressure (SBP) $\geq 140 \mathrm{mmHg}$ and/or diastolic blood pressure (DBP) $\geq 90 \mathrm{mmHg}$. In recent years, with the emphasis on SBP and the development of arterial elasticity function, pulse pressure (PP), which is an indicator of arterial elasticity function, has become a research hotspot in the field of CVDs. As an independent risk factor in the study of CVD and cerebrovascular diseases, $\mathrm{PP}$ has greater predictive value than do SBP and DBP, especially for the elderly population. PP could be used to predict the occurrence of CVD caused by atherosclerosis, which has been used as an important indicator for predicting the incidence and mortality of CVD (Kannel et al., 1971; Franklin et al., 1997; Fang et al., 2000; Anan et al., 2008).

Advanced hypertension can cause left ventricular hypertrophy, thereby leading to heart failure. In recent years, B-type brain natriuretic peptide (BNP) has become widely used for the diagnosis of heart failure, which has important diagnostic value. Ventricular hypertrophy can cause an increase in filling pressure; BNP is mainly synthesized and secreted by left ventricular myocardial cells in normal people, and the level of BNP changes with increased filling pressure. BNP plays a physiological role through the dilation of blood vessels, increasing natriuresis, and inhibition of the water and sodium retention effect of 
adrenalin- and renin-angiotensin; therefore, elevated BNP levels play a role in protecting the body during hypertension, and BNP is closely related to hypertension. Moreover, the levels of BNP are mainly determined by the natriuretic peptide precursor B (NPPB) gene; therefore, in this study, we investigated the correlation between the NPPB gene and the incidence of hypertension.

\section{MATERIAL AND METHODS}

\section{Patients}

\section{Hypertensive group}

Between October 2009 and March 2011, 180 patients (mean age \pm SD: $59.92 \pm 12.30$ years; $47 \%$ men) with hypertension were recruited for the study. The inclusion criteria, according to the criterion of China's prevention and care guidelines of hypertension, were as follows: i) patients with a mean SBP $\geq 140 \mathrm{mmHg}$ or DBP $\geq 90 \mathrm{mmHg}$ from three measurements over different days before treatment, and ii) patients with a previous hypertension history who were receiving antihypertensive drug treatment. The exclusion criteria were as follows: patients with secondary hypertension, severe anemia, obesity, hyperthyroidism, valvulopathy, congenital heart disease, myocardosis, arteriovenous fistula, constriction of pericardial sac phlogistic, pericardial effusion, serious arrhythmia, peripheral vascular disease, diabetes, myocardial infarction, congestive heart failure, and severe heart and kidney disease that could not tolerate examinations.

\section{Normotensive group}

The normotensive (control) group comprised 540 individuals (mean age \pm SD: 58.75 \pm 12.72 years; $48 \%$ men) recruited from individuals who came to the First Affiliated Hospital of Fujian Medical University for health physical examinations during the same time period. Subjects were included according to China's prevention and care guideline of hypertension: individuals with normal routine examination results, no organic diseases, $\mathrm{SBP}<140 \mathrm{mmHg}$, and $\mathrm{DBP}<90 \mathrm{mmHg}$.

\section{DNA extraction}

DNA isolation kits supplied by Xiamen Taijing Biological Technology Co. Ltd. were used to extract DNA from the peripheral blood of patients and controls, which was anticoagulated in EDTA and stored at $-20^{\circ} \mathrm{C}$.

\section{Polymerase chain reaction (PCR) primers and conditions}

The Primer Express software was applied to design the following primers for PCR: upstream primer, 5'-aag gag gca ctg gga gag ggg aat-3' and downstream primer, 5'-ccc cac caa gec aac aca gga tgg a-3' (synthesized by Shanghai ShengGong Biological Engineering Service Co. Ltd.). The product amplified by the primers was a 429-bp DNA sequence of the NPPB 
gene from -1299 bp upstream of the initial point to the -895 -bp position. The PCR system was $50 \mu \mathrm{L}$, containing $0.5 \mu \mathrm{L}$ upstream and downstream primers, $5 \mu \mathrm{L}$ buffer solution, $4 \mu \mathrm{L}$ magnesium chloride, $1 \mu \mathrm{L}$ template, $1 \mu \mathrm{L}$ dNTP, $0.5 \mu \mathrm{L}$ Taq enzyme, and double-distilled water. The conditions of the reaction system were as follows: $5 \mathrm{~min}$ initial denaturation at $94^{\circ} \mathrm{C} ; 30$ cycles each of $1 \mathrm{~min}$ denaturation at $94^{\circ} \mathrm{C}$, annealing for $30 \mathrm{~s}$ at $52^{\circ} \mathrm{C}$, and extension for $1 \mathrm{~min}$ at $72^{\circ} \mathrm{C}$; followed by a final extension for $2 \mathrm{~min}$ at $72^{\circ} \mathrm{C}$. The products were subjected to $1.5 \%$ agar gel electrophoresis to observe the results.

\section{Sequencing}

The PCR products were sequenced by the Shanghai ShengGong Biological Engineering Service Co. Ltd.

\section{General clinical characteristics}

For all individuals, blood pressure, height, weight, non-fasting triglycerides (TG), non-fasting cholesterol (Chol), non-fasting glucose (Gluc), creatinine (Cr), uric acid, heart rate (HR), smoking history, and alcohol drinking habits were recorded. For hypertensive patients, the condition of drug treatment and history of hypertension was recorded.

\section{Statistical analysis}

Data are reported as means \pm SD and were subjected to a homogeneity test of variance. Based on the homogeneity test of variance, means were compared with the Student $t$-test or the $t$-test. Direct counting was used to calculate gene frequencies in normal and hypertension groups. Gender, Hardy-Weinberg equilibrium, and gene frequencies were compared between groups with the $\chi^{2}$ test. $\mathrm{P}<0.05$ represented a statistically significant result. All statistical analyses were conducted with the SPSS15.0 software.

\section{RESULTS}

\section{General clinical characteristics}

The Levene homogeneity test of variance was used to evaluate data of hypertension and normal groups. If the variance was equal, the Student $t$-test was employed to compare groups, if not, the $t$-test was used. Results showed that the mean PP, angiosthenia, age, and $\mathrm{Cr}$ levels were significantly different between the two groups, whereas the other clinical characteristics showed no significant differences (Table 1).

\section{Comparison of age and gender with respect to different PP levels}

In the hypertension group and the normal group, age differed significantly among the different PP groups, with the mean age increasing with increasing PP levels. None of the other indexes showed significant effects (Tables 2 and 3). The distribution of the NPPB gene sequence is shown in Figure 1. 


\begin{tabular}{|c|c|c|c|}
\hline & Hypertensive group & Normotensive group & $\mathrm{P}$ \\
\hline Gender (male/female) & $85 / 95$ & $262 / 278$ & 0.763 \\
\hline Age (years) & $59.92 \pm 12.30$ & $58.75 \pm 12.72$ & 0.282 \\
\hline BMI $\left(\mathrm{kg} / \mathrm{m}^{2}\right)$ & $24.38 \pm 2.72$ & $24.35 \pm 2.62$ & 0.895 \\
\hline $\mathrm{TG}(\mathrm{mM})$ & $1.51 \pm 0.83$ & $1.52 \pm 0.98$ & 0.902 \\
\hline Chol (mM) & $5.04 \pm 0.94$ & $4.99 \pm 0.85$ & 0.506 \\
\hline Glu (mM) & $5.14 \pm 0.84$ & $5.10 \pm 0.50$ & 0.441 \\
\hline Uric acid $(\mu \mathrm{M})$ & $348.45 \pm 91.43$ & $340.87 \pm 81.84$ & 0.297 \\
\hline $\mathrm{Cr}(\mu \mathrm{M})$ & $82.95 \pm 22.22$ & $76.28 \pm 16.10$ & 0.000 \\
\hline $\mathrm{MAP}(\mathrm{mmHg})$ & $106.62 \pm 11.53$ & $89.45 \pm 9.97$ & 0.000 \\
\hline $\mathrm{PP}(\mathrm{mmHg})$ & $54.78 \pm 14.43$ & $43.48 \pm 11.73$ & 0.000 \\
\hline HR (bpm) & $74.69 \pm 7.68$ & $75.38 \pm 8.90$ & 0.352 \\
\hline
\end{tabular}

$\mathrm{BMI}=$ body mass index $; \mathrm{TG}=$ triglycerides $; \mathrm{Chol}=$ non-fasting cholesterol $; \mathrm{Glu}=$ non-fasting glucose $\mathrm{Cr}=$ creatinine; $\mathrm{MAP}=$ mean arterial pressure; $\mathrm{PP}=$ pulse pressure; $\mathrm{HR}=$ heart rate.

Table 2. Clinical data of hypertensive patients.

\begin{tabular}{lccc}
\hline & \multicolumn{3}{c}{ Hypertensive group } \\
\cline { 2 - 4 } & $<40 \mathrm{mmHg}$ & $40-60 \mathrm{mmHg}$ & $\geq 60 \mathrm{mmHg}$ \\
\hline Age & $58.65 \pm 12.45$ & $59.85 \pm 12.15$ & $63.05 \pm 12.20^{*}$ \\
Cases & 26 & 86 & 68 \\
BMI $\left(\mathrm{kg} / \mathrm{m}^{2}\right)$ & $24.65 \pm 2.84$ & $24.58 \pm 2.83$ & $24.35 \pm 2.70$ \\
TG $(\mathrm{mM})$ & $1.65 \pm 0.93$ & $5.62 \pm 0.88$ & $1.63 \pm 0.81$ \\
Chol $(\mathrm{mM})$ & $5.55 \pm 0.87$ & $5.08 \pm 0.90$ & $5.11 \pm 1.00$ \\
Glu $(\mathrm{mM})$ & $5.08 \pm 0.73$ & $347.0 \pm 0.82$ & $5.22 \pm 0.81$ \\
Uric acid $(\mu \mathrm{M})$ & $374.5 \pm 85.34$ & $81.85 \pm 22.81$ & $350.5 \pm 93.19$ \\
Cr $(\mu \mathrm{M})$ & $83.56 \pm 22.05$ & $74.88 \pm 7.86$ & $84.28 \pm 21.65$ \\
HR $(\mathrm{bpm})$ & $77.94 \pm 6.82$ & & $72.29 \pm 7.67$ \\
\hline
\end{tabular}

$* \mathrm{P}<0.05$. For abbreviations, see legend to Table 1 .

Table 3. Clinical data of the normotensive group (controls).

\begin{tabular}{lccc}
\hline & \multicolumn{3}{c}{ Normotensive group } \\
\cline { 2 - 4 } & $<40 \mathrm{mmHg}$ & $40-60 \mathrm{mHg}$ & $\geq 60 \mathrm{mmHg}$ \\
\hline Age & $56.65 \pm 11.91$ & $59.79 \pm 12.22$ & $71.68 \pm 10.62^{*}$ \\
Cases $(\mathrm{N})$ & 52 & 263 & 225 \\
BMI $\left(\mathrm{kg} / \mathrm{m}^{2}\right)$ & $24.20 \pm 2.53$ & $24.38 \pm 2.63$ & $23.69 \pm 2.68$ \\
TG $(\mathrm{mM})$ & $1.69 \pm 0.83$ & $1.55 \pm 1.25$ & $1.63 \pm 1.02$ \\
Chol $(\mathrm{mM})$ & $4.91 \pm 0.89$ & $5.10 \pm 0.46$ & $5.16 \pm 0.66$ \\
Glu $(\mathrm{mM})$ & $5.14 \pm 0.48$ & $5.10 \pm 0.85$ & $5.20 \pm 0.81$ \\
Uric acid $(\mu \mathrm{M})$ & $333.76 \pm 81.43$ & $343.23 \pm 81.90$ & $354.64 \pm 81.92$ \\
Cr $(\mu \mathrm{M})$ & $76.05 \pm 17.32$ & $76.32 \pm 15.84$ & $76.87 \pm 13.01$ \\
HR $(\mathrm{bpm})$ & $75.90 \pm 9.23$ & $75.12 \pm 9.04$ & $73.93 \pm 6.47$ \\
\hline
\end{tabular}

$* \mathrm{P}<0.05$. For abbreviations, see legend to Table 1 .

\section{Distribution of genotypes in hypertension and normal groups}

As shown in Table 4, 70.6\% of the 180 patients had the GG homozygous genotype, $26.7 \%$ were GT heterozygotes, and $2.7 \%$ were TT homozygotes. The distribution frequency of the three genotypes did not differ significantly from the expected values under HardyWeinberg equilibrium. This suggested that the large, random sample was representative of the general population. 

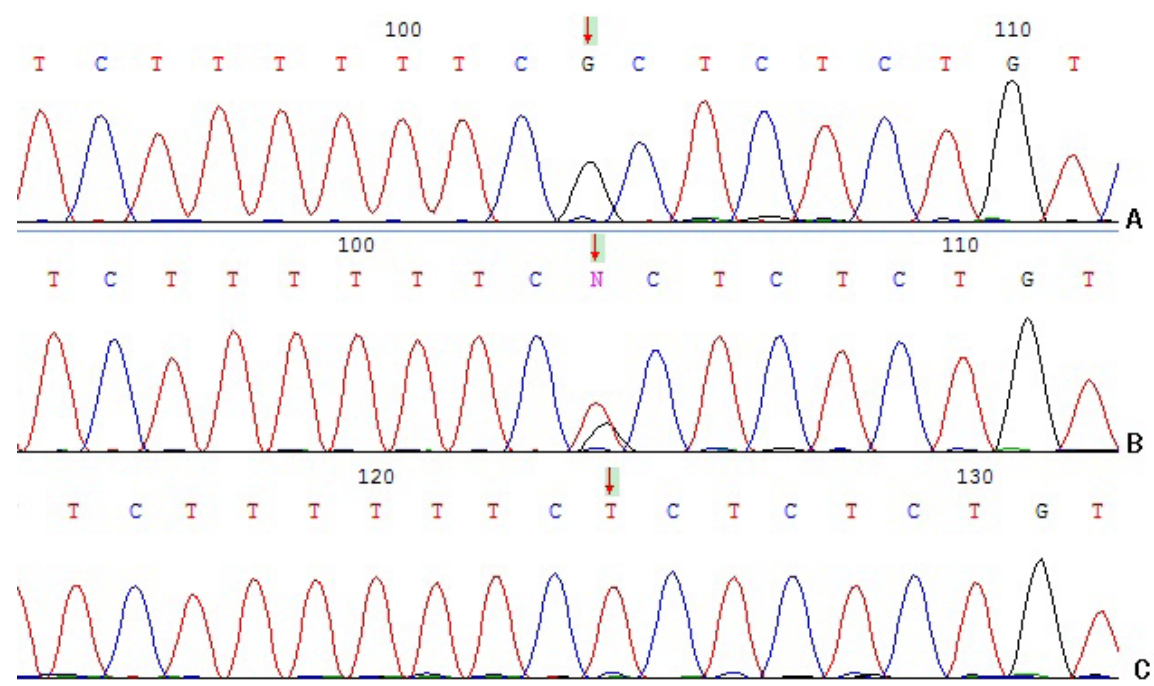

Figure 1. Distribution of the 5'-NPPB gene sequence. A. GG genotype; B. TT genotype; C. GT genotype.

Table 4. Genotype distribution in the hypertensive and normotensive groups.
\begin{tabular}{lcccr}
\hline Group & \multicolumn{3}{c}{ Genotype (\%) } \\
\cline { 3 - 4 } & Cases (N) & GG & GT & TT \\
\hline Hypertensive & 180 & $127(70.6 \%)$ & $48(26.7 \%)$ & $5(2.7 \%)$ \\
Normotensive & 540 & $355(65.7 \%)$ & $163(30.2 \%)$ & $22(4.1 \%)$ \\
\hline
\end{tabular}

\section{Allele frequency distribution in hypertension and normal groups}

In the hypertension group, the $\mathrm{G}$ allele frequency was higher than in the normal group, while the $\mathrm{T}$ allele frequency was lower than that in the normal group; however, the differences were not statistically significant. This result could not indicate that the $\mathrm{G}$ allele is a risk factor for primary hypertension and that the $\mathrm{T}$ allele is a protective allele. Therefore, we analyzed the genotype distribution in the two groups. We combined the GT genotype with the TT genotype, and subdivided the hypertension and normal groups based on the presence of the $\mathrm{T}$ allele, resulting in a GG genotype group and a GT+TT genotype group. The chi-square test was then used to compare the frequency distributions (Tables 5 and 6).

Table 5. Allele frequency distribution in the hypertensive and normotensive groups.

\begin{tabular}{|c|c|c|c|}
\hline & \multirow[t]{2}{*}{ Number of alleles } & \multicolumn{2}{|c|}{ Allele frequency } \\
\hline & & $\mathrm{G}$ & $\mathrm{T}$ \\
\hline Hypertensive & 360 & $302(83.9 \%)$ & $58(16.1 \%)$ \\
\hline Normotensive & 1080 & $873(80.8 \%)$ & $207(19.2 \%)$ \\
\hline$\chi_{\mathrm{P}}^{\chi^{2}}$ & & & \\
\hline
\end{tabular}


Table 6. Genotype distribution in the hypertensive and normotensive groups.

\begin{tabular}{lcccc}
\hline Group & Cases of GG genotype (N) & Cases of GT+TT genotype (N) & $\chi^{2}$ & P \\
\hline Hypertensive & 128 & 52 & 1.763 & 0.184 \\
Normotensive & 355 & 185 & & \\
\hline
\end{tabular}

\section{Clinical indexes of different genotypes in the hypertension group}

As shown in Table 7, the body mass index [BMI; weight $(\mathrm{kg}) /$ height $\left.\left(\mathrm{m}^{2}\right)\right]$, TG, Chol, uric acid, Cr, mean arterial pressure (MAP), PP, and HR did not differ significantly among genotypes in the hypertension group.

\begin{tabular}{|c|c|c|c|}
\hline \multirow[t]{2}{*}{ Clinical data } & \multicolumn{2}{|c|}{ Genotype } & \multirow[t]{2}{*}{$\mathrm{P}$} \\
\hline & GG & $\mathrm{GT}+\mathrm{TT}$ & \\
\hline BMI $\left(\mathrm{kg} / \mathrm{m}^{2}\right)$ & $24.55 \pm 2.92$ & $24.35 \pm 2.73$ & 0.672 \\
\hline $\mathrm{TG}(\mathrm{mM})$ & $1.61 \pm 0.63$ & $1.60 \pm 0.42$ & 0.916 \\
\hline Chol (mM) & $4.94 \pm 0.63$ & $5.11 \pm 0.81$ & 0.114 \\
\hline Glu (mM) & $5.19 \pm 0.44$ & $5.29 \pm 0.51$ & 0.068 \\
\hline Uric acid $(\mu \mathrm{M})$ & $346.76 \pm 61.67$ & $357.62 \pm 87.17$ & 0.343 \\
\hline $\operatorname{Cr}(\mu \mathrm{M})$ & $79.68 \pm 17.89$ & $83.22 \pm 23.72$ & 0.190 \\
\hline MAP (mmHg) & $107.90 \pm 9.16$ & $111.10 \pm 12.04$ & 0.118 \\
\hline PP $(\mathrm{mmHg})$ & $58.20 \pm 13.52$ & $55.10 \pm 15.74$ & 0.187 \\
\hline HR (bpm) & $73.71 \pm 9.42$ & $75.84 \pm 6.38$ & 0.136 \\
\hline
\end{tabular}

For abbreviations, see legend to Table 1.

\section{Clinical indexes of different gene types in the normal group}

BMI, TG, Chol, uric acid, Cr, and MAP did not differ significantly among genotypes in the normal group. However, PP was significantly higher in individuals with the GG genotype than in the GT+TT genotype (Table 8).

\begin{tabular}{lrrr}
\multicolumn{2}{c}{ Table 8. Relationship between genotype and clinical data in normotensive patients. } \\
\cline { 2 - 3 } Clinical data & \multicolumn{1}{c}{ Genotype } & P \\
\cline { 2 - 3 } & $24.290 \pm 2.97$ & GT+TT & 0.349 \\
\hline BMI $\left(\mathrm{kg} / \mathrm{m}^{2}\right)$ & $1.47 \pm 0.88$ & $1.59 \pm 2.78$ & 0.194 \\
TG $(\mathrm{mM})$ & $4.96 \pm 0.82$ & $5.01 \pm 0.86$ & 0.294 \\
Chol $(\mathrm{mM})$ & $5.12 \pm 0.48$ & $5.07 \pm 0.28$ & 0.192 \\
Glu $(\mathrm{mM})$ & $355.43 \pm 75.37$ & $342.80 \pm 82.42$ & 0.074 \\
Uric acid $(\mu \mathrm{M})$ & $81.17 \pm 18.61$ & $79.62 \pm 21.46$ & 0.384 \\
Cr $(\mu \mathrm{M})$ & $92.93 \pm 8.99$ & $91.91 \pm 10.79$ & 0.244 \\
MAP $(\mathrm{mmHg})$ & $49.10 \pm 7.43$ & $41.70 \pm 1.34$ & 0.000 \\
PP $(\mathrm{mmHg})$ & $75.20 \pm 8.82$ & $75.50 \pm 7.62$ & 0.695 \\
HR $(\mathrm{bpm})$ & &
\end{tabular}

For abbreviations, see legend to Table 1.

\section{DISCUSSION}

In recent years, with progress in the study of arterial elasticity and increasing attention paid to SBP in hypertension treatment, PP, the index of arterial elasticity, has become a 
research hotspot in the field of hypertension. Wu et al. analyzed data related to hypertension from individuals from a rural population and from Beijing ( $N=29,707$; age, 35-74 years), and found that increased PP may be a high risk factor for CVD and arteriosclerosis. After adjusting for factors such as gender, age, history of heart disease, and smoking history, PP remained positively correlated with the incidence of CVD, especially in the patients older than 60 years (Conneally, 2003).

Many factors can affect PP; however, studies evaluating the relationship between genes and PP are rare. Sudoh et al. (1988) and Safar et al. (2004) found that the angiotensin II one receptor gene $(A T 1)$ and the endothelial nitric oxide synthase gene (eNOS) could affect the relationship between PP and age, which may increase the risk of CVD. Safar et al. (2004) found that polymorphisms of genes could influence the relationship between PP and age, which in turn influenced the risk of CVD (Maisel et al., 2001). Together, these results suggested a novel and complicated interaction among genes as a mechanistic factor influencing the risk of CVD.

Researchers have found mutations and polymorphisms in the NPPB gene and other genes of the natriuretic peptide system in hypertension patients (Okamoto et al., 2000; Chan et al., 2004; Seino et al., 2004). Jeunemaitre et al. (1992) found that the BNP level in the hypertension group was higher than that in the control group. Redfield et al. (2002) reported that BNP levels increased with increasing age, and that BNP levels were higher in women than in men. In the Japanese population, some researchers reported correlations between BNP levels and age, natriuresis, and higher blood pressure (Eguchi et al., 2004; Kanda et al., 2005). In addition, higher BNP levels were suggested to increase the risk of CVD in men, but not in women (Freitag et al., 2003). Kosuge et al. (2007) reported that one variable number of tandem repeat polymorphism site in the flanking region of the NPPB gene 5'-end was related to primary hypertension in Japanese women. The mutation in the NPPB gene or in its upstream regulatory sequence may lead to changes in baseline BNP levels, which influences blood pressure. Therefore, the NPPB gene has been proposed as a candidate gene for primary hypertension incidence. The polymorphism site in the flanking region of the NPPB gene's 5'end, rs375381, is 1991 bp away from the transcription site; its upstream region includes a TCenrichment region and its downstream region includes an Alu sequence. Both of these regions are regulatory regions of the NPPB gene. Therefore, this polymorphic site may be correlated with the incidence of hypertension.

In this study, the polymorphism rs375381 in the flanking region of the NPPB 5'-end was evaluated with respect to hypertension. Compared with the control group, $\mathrm{Cr}$ levels in the blood, MAP, and PP were all significantly higher in the hypertension group. In both the hypertension and control groups, age differed significantly among the different $\mathrm{PP}$ groups (P $<0.05$ ), with mean age increasing with increasing PP, which agrees with results of previous studies. Few studies have investigated the frequency of different genotypes of the c.-1298 G/T polymorphism site of the NPPB gene. Our study is the first to report the distribution of the c.-1298 G/T polymorphism site of the NPPB gene in hypertension patients and normal individuals. Subjects were divided based on genotype in the hypertension and control groups, and the association between different clinical characteristics and genotypes was statistically evaluated. The results showed that the distribution of genotypes and alleles did not differ significantly in the hypertension or control groups. The PP of individuals with the GG genotype was significantly higher than that of individuals with the GT+TT genotype in the control 
group; none of the other indices showed statistically significant differences with respect to genotype in the control group.

Hypertension is a polygenic disease, which results from interactions between genetic and environmental factors. Once the effects of these factors accumulate to a certain extent, genes can show abnormal expression patterns and blood pressure rises to pathological levels. In most conditions, abnormal polygene expression leads to increases in blood pressure. The abnormal expression of one gene could affect the expression of other genes through a compensatory mechanism. Therefore, the incidence of hypertension and some macroscopic indexes, such as MAP and PP, cannot accurately reflect the abnormal expression of a single gene.

Furthermore, although the renin-angiotensin-aldosterone system is a major regulatory factor for arterial blood pressure, BNP can induce the vasoconstrictive action of the renin-angiotensin-aldosterone system and combine with atrial natriuretic peptide as a major endocrine system, resulting in volume overload and hypertension. The NPPB gene has been proposed to play a key role in individual differences in BNP levels and as a candidate gene of hypertension incidence. Although 23 polymorphic sites have been found in the NPPB gene, only one of these sites has been studied, and the effect of the others have not yet been elucidated. More in-depth study is required on whether these different polymorphisms interact, the degree of their interaction, and their contribution to the expression of the NPPB gene.

Recent developments in genetic research have revealed the concept of minor gene effects in primary hypertension, diabetes mellitus, and other polygenic diseases. A minor gene is one whose effect has little influence on phenotype, and whose single function cannot be distinguished in a polygene. In addition, some researchers have adopted a linkage disequilibrium method for studying genetic polymorphisms. This involves the analysis of multiple SNP sites of one gene in one population, and integrating the concept of haplotype on the basis of the permutation condition of multiple SNP sites and the major permutation distribution frequency in the population in order to study the relationship between permutations and clinical characteristics.

BNP functions in diuresis, natriuresis, and as a vasorelaxant and inhibits the activity of the renin-angiotensin-aldosterone system, adrenocortical hormone release, and overreaction of the sympathetic nerve. It can also reduce the extent of endothelial cell injury. Therefore, individuals with abnormal BNP genes have a higher risk of developing hypertension.

\section{ACKNOWLEDGMENTS}

We gratefully acknowledge the financial support of the Natural Science Foundation of Fujian Province, China (Grant \#2009J01159, \#2012J01370, \#2012Y4003).

\section{REFERENCES}

Anan F, Masaki T, Eto T, Fukunaga N, et al. (2008). Postchallenge plasma glucose and glycemic spikes are associated with pulse pressure in patients with impaired glucose tolerance and essential hypertension. Hypertens. Res. 31: 1565-1571.

Chan CP, Sanderson JE, Glatz JF, Cheng WS, et al. (2004). A superior early myocardial infarction marker. Human hearttype fatty acid-binding protein. Z. Kardiol. 93: 388-397.

Conneally PM (2003). The complexity of complex diseases. Am. J. Hum. Genet. 72: 229-232.

Eguchi K, Kario K, Hoshide S, Hoshide Y, et al. (2004). Greater change of orthostatic blood pressure is related to silent cerebral infarct and cardiac overload in hypertensive subjects. Hypertens. Res. 27: 235-241.

Fang J, Madhavan S and Alderman MH (2000). Pulse pressure: a predictor of cardiovascular mortality among young normotensive subjects. Blood Press 9: 260-266. 
Franklin SS, Gustin W, Wong ND, Larson MG, et al. (1997). Hemodynamic patterns of age-related changes in blood pressure. The Framingham Heart Study. Circulation 96: 308-315.

Freitag MH, Larson MG, Levy D, Benjamin EJ, et al. (2003). Plasma brain natriuretic peptide levels and blood pressure tracking in the Framingham Heart Study. Hypertension 41: 978-983.

Jeunemaitre X, Soubrier F, Kotelevtsev YV, Lifton RP, et al. (1992). Molecular basis of human hypertension: role of angiotensinogen. Cell 71: 169-180.

Kanda H, Kita Y, Okamura T, Kadowaki T, et al. (2005). What factors are associated with high plasma B-type natriuretic peptide levels in a general Japanese population? J. Hum. Hypertens. 19: 165-172.

Kannel WB, Gordon T and Schwartz MJ (1971). Systolic versus diastolic blood pressure and risk of coronary heart disease. The Framingham study. Am. J. Cardiol. 27: 335-346.

Kosuge K, Soma M, Nakayama T, Aoi N, et al. (2007). A novel variable number of tandem repeat of the natriuretic peptide precursor B gene's 5'-flanking region is associated with essential hypertension among Japanese females. Int. J. Med. Sci. 4: 146-152.

Maisel AS, Koon J, Krishnaswamy P, Kazenegra R, et al. (2001). Utility of B-natriuretic peptide as a rapid, point-of-care test for screening patients undergoing echocardiography to determine left ventricular dysfunction. Am. Heart J. 141: 367-374.

Okamoto F, Sohmiya K, Ohkaru Y, Kawamura K, et al. (2000). Human heart-type cytoplasmic fatty acid-binding protein (H-FABP) for the diagnosis of acute myocardial infarction. Clinical evaluation of H-FABP in comparison with myoglobin and creatine kinase isoenzyme MB. Clin. Chem. Lab. Med. 38: 231-238.

Redfield MM, Rodeheffer RJ, Jacobsen SJ, Mahoney DW, et al. (2002). Plasma brain natriuretic peptide concentration: impact of age and gender. J. Am. Coll. Cardiol. 40: 976-982.

Safar ME, Lajemi M, Rudnichi A, Asmar R, et al. (2004). Angiotensin-converting enzyme D/I gene polymorphism and age-related changes in pulse pressure in subjects with hypertension. Arterioscler. Thromb. Vasc. Biol. 24: 782-786.

Seino Y, Tomita Y, Takano T and Ohbayashi K (2004). Office cardiologists cooperative study on whole blood rapid panel tests in patients with suspicious acute myocardial infarction: comparison between heart-type fatty acid-binding protein and troponin T tests. Circ. J. 68: 144-148.

Sudoh T, Kangawa K, Minamino N and Matsuo H (1988). A new natriuretic peptide in porcine brain. Nature 332: 78-81.

Wu GX, Wu ZS, Liu J, Zeng ZC, et al. (2001). A cohort study of the distribution feature on pulse pressure. Zhonghua Xin Xue Guan Bing Za Zhi 29: 436-440. 